\title{
Molecular Therapeutic Potency of Metformin by Targeting p53-Related Molecules in Mutant p53 Colon Cancer Cell Line
}

\author{
Dyah R. Budiani ${ }^{1 *}$, Melani R. Mahanani ${ }^{1}$, Yohanes C. Wibowo ${ }^{1}$, Ari Probandari ${ }^{2}$, \\ Diding H. Prasetyo ${ }^{3}$, Ambar Mudigdo ${ }^{1}$ \\ ${ }^{\mathbf{1}}$ Department of Anatomical Pathology, Faculty of Medicine Sebelas Maret Universitym Surakarta, Indonesia \\ ${ }^{2}$ Department of Public Health, Faculty of Medicine Sebelas Maret University, Surakarta, Indonesia \\ ${ }^{3}$ Department of Biochemistry, Faculty of Medicine Sebelas Maret University, Surakarta, Indonesia
}

\begin{abstract}
Colon cancer is a malignancy in gastrointestinal tract. It causes high mortality rate in global cancer population. However, chemotherapy as its first option therapy is still controversial due to its effectiveness and its adverse effects. Finding supportive and alternative drugs to cure cancer is one of focus in cancer research. A drug which also has anticancer effects is metformin. Metformin is a biguanide antidiabetic which show its potential anticancer benefit in metabolic-related cancers including colon cancer. To investigate anticancer potency of metformin in targeting p53-related molecules. Metformin treatment were divided into 4 groups by $0,5,10$ and $20 \mathrm{mM}$ concentrations and incubated in $37^{\circ} \mathrm{C}$ and $5 \% \mathrm{CO}_{2}$ condition for 48 hours. Immunohistochemistry were conducted to asses level of expression of Bax, p2I, cyclin DI and E2FI, respectively. Level of expression were measured by $\mathrm{H}$-SCORE using percentage and intensity calculation. Comparisons of H-SCORE between groups were performed by ANOVA for parametrical data and Kruskal-Wallis for nonparametrical data. Growth inhibition were observed after metformin treatment. Metformin increases Bax expression significantly at all concentrations. p2I expression was also increased after metformin treatment but is not statistically significant. Subsequently, metformin decreases cyclin DI expression at 10 and $20 \mathrm{mM}$ concentration thus decreased E2FI expression at 5 and $10 \mathrm{mM}$ concentration. These data suggest that metformin may have potential therapeutic effects in mutant $\mathrm{p} 53$ colon cancer cell line by targeting $\mathrm{p} 53$-related molecules.
\end{abstract}

Keywords: Colon cancer, p53, Biguanide, Metformin, p53-mutant cell line

\section{INTRODUCTION}

Colon cancer is malignancy in the gastrointestinal tract which cause high mortality rates in global cancer population. Colon cancer is third most common cancer in males and the second in females. Colon cancer incidence was decreased in recent years in developed countries due to increase of patient treatment quality and early detection. Unfortunately, incidence of colon cancer in low risk area which include developing countries was increased.

Chemotherapy remains one of therapeutic option for colon cancer treatment. Chemotherapy act as adjuvant by reducing risk of relapse and patient death. Therefore, use of chemotherapy is still controversial due to its effectiveness and adverse effects. As reported by O'Connor, et al, no survival benefit were found in stage II colon cancer patients with poor prognostic features nor for no poor prognostic features after chemotherapy treatment. Moreover, some colon cancer chemotherapy regimen such as 5-fluorouracil (5-FU) could cause fatal adverse effect.

\footnotetext{
*Corresponding author e-mail: dyahrb@yahoo.com
} 
Metformin is a biguanide which has potential anticancer effect. Landman, et al reported that use of metformin related to lower cancer risk in diabetes type II patient. More specific, Zhang, et al., reported use of metformin reduced risk of colon cancer significantly. Interestingly, metformin could has benefit to non-diabetic patients also as suggested by Hosono, et al.

In their study, metformin inhibited growth of colon cancer marker, aberrant crypt foci (ACF), consistently with decreased proliferating cell nuclear antigen index.

In vitro study could help to understand underlying molecular anticancer mechanism of metformin. Alimova, et al,. found that cytotoxic effect of metformin in breast cancer cell line influenced by cell cycle arrest and altered erbB2 receptor tyrosine kinase (RTK) pathways. Cytotoxic effect of metformin were also found in p53-deficient colon cancer cell line. Zakikhani, et al., reported inhibition of colon cancer cell line consistent with increased AMP-activated protein kinase (AMPK) activity.

In present study, we investigate potential anticancer of metformin in p53-deficient colon cancer cell line by assess the following p53related molecules: p21 (a cyclin-dependent kinase inhibitor) and Bax (a pro-apoptotic molecule). We also assess an oncogenic molecules expression, cyclin D1 and E2F1 which is downstream target of cyclin D1.

\section{MATERIALS AND METHODS}

\section{Antibodies.}

Mouse monoclonal antibodies included antihuman cyclin D1 and anti-human E2F1 from Neomarker (CA, USA), anti-human p21 and anti-human Bax from Biocare (Concord, CA, USA).

\section{Reagents}

Metformin was obtained from Dr. Endang Lukitaningsih, Faculty of Pharmacy, Gadjah Mada University, Indonesia. It was used across a range of concentrations at 5, 10 and $20 \mathrm{mM}$ diluted in media.

\section{Cell line and culture conditions}

The human colon cancer line WiDr was obtained from Parasitology Laboratory of Gadjah Mada University in Indonesia. Cell line was maintained in RPMI1640 medium supplemented with $10 \%$ fetal bovine serum (FBS) cultured at $37^{\circ} \mathrm{C}$ humidified atmosphere containing $95 \%$ air and $5 \% \mathrm{CO}_{2}$. Cells were passaged by $0.25 \%$ Trypsin-EDTA when they reached $80 \%$ confluence. Chemicals were purchased from Neomarker (CA, USA).

\section{Cell proliferation assay}

Cells were plated onto 96-well plates at $3.5 \mathrm{x}$ $10^{4}$ cells well. After 24 hours in culture, the medium was removed and replaced by medium with (treatment) or without (control) metformin for 48 hours. The effect of metformin on WiDr cell line was evaluated by MTT assay (3-(4,5dimethylthiazol-2-yl)-2,5-diphenyltetrazolium bromide), wells were read at $490 \mathrm{nM}$ with a microplate reader. The percentages of surviving cells from each group relative to control defined as $100 \%$ survival.

\section{Immunohistochemistry}

Protein expression of Bax, p21, cyclin D1, and E2F1 was assessed by using immunohistochemistry staining against monoclonal antibodies anti-human Bax, p21, cyclin D1, and E2F1. Methanol-fixed cells were stained with hematoxylin and eosin evaluated microscopically. After Bax, p21, cyclin D1, and E2F1 primary antibodies, the secondary antibody was anti-mouse and third step was ABC complex (Streptavidin-Biotin peroxidase) and DAB (3,3'-diaminobenzidine) chromogen. Scores of immunostaining were calculated by multiplying the percentage of labeled cells with the intensity $(1+, 2+, 3+)$ of staining for a total score gain from 0 to 300 . Thus the formula could be aplied by:

$\mathrm{H}-\mathrm{SCORE}=(3 \times \%$ of strong intensity cells $)+(2 x \%$ of moderate intensity cells $)+(1$ 
$\mathrm{x}$ weak intensity cells $)+(0 \mathrm{x}$ negative intensity cells).

\section{Statistical analysis}

$=$ Values are expressed as the mean $\pm \mathrm{SD}$ in the bar graphs. The significance of the difference between the control and each experimental test condition was analyzed by ANOVA and Kruskall-Wallis test and $p<0.05$ was considered statistically significant.

\section{RESULTS}

\section{Metformin induces growth inhibition of colon cancer cell line}

As shown in Fig. 1, metformin inhibits growth of WiDr cell line in a dose dependent manner. Three metformin concentrations $(5 \mathrm{mM}, 10$ $\mathrm{mM}$, and $20 \mathrm{mM}$ ) significantly reduced WiDr cell line viability.

\section{Metformin increases apoptotic activity by inducing Bax expression levels}

Apoptotic activity of WiDr cell line was significantly increased after metformin treatment as shown by Fig. 2 increased Bax expression levels. Bax was increased at 5 and $10 \mathrm{mM}$ metformin concentrations. Maximum Bax expression levels were observed at $20 \mathrm{mM}$ concentration.

\section{Metformin inhibits cell cycle-related molecule and increases its inhibitor}

Metformin shown to influence cell cycle activity by targeting cyclin D1 and p21 (Fig. 3). Metformin significantly inhibited cyclin D1 expression at $10 \mathrm{mM}$ and $20 \mathrm{mM}$. Decreased cyclin D1 expression was also found at $5 \mathrm{mM}$ metformin but is not statistically significant. Consistent with decreased cyclin D1 expression, metformin induces p21 expression but is not statistically significant between groups.

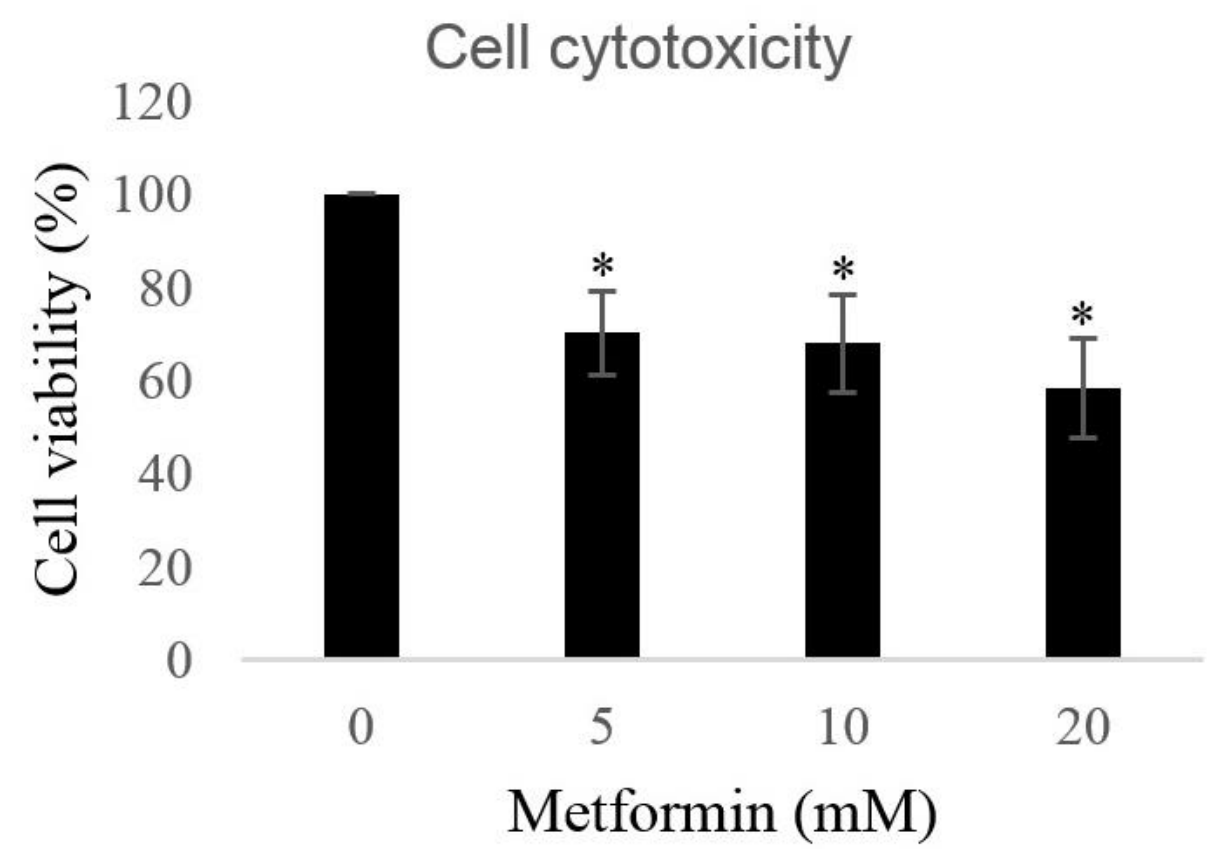

Figure I. Metformin induces growth inhibition of colon cancer cell line. WiDr cell line were seeded onto 96-well plates and treated by metformin followed by incubation at $37^{\circ} \mathrm{C}$ with $5 \% \mathrm{CO}_{2}$. The effects of metformin treatment were assessed by MTT assay after 24 hours. Data presented as mean \pm standard deviation. $* p<0.05$ versus control. 


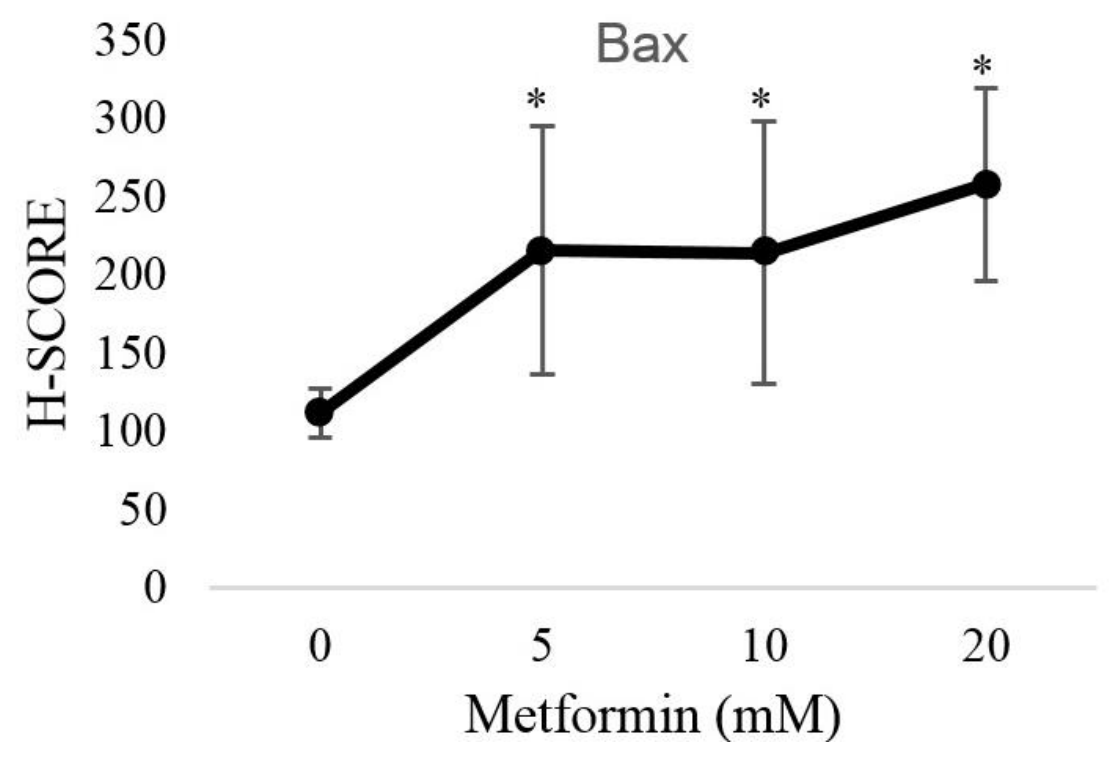

Figure 2. Metformin increases Bax expression levels. After metformin treatment, IHC was conducted to assess Bax expression. Cell percentage and intensity were calculated to measure H-SCORE. Data presented as mean \pm standard deviation. $* p<0.05$ versus control.

\section{Cyclin D1 and p21}

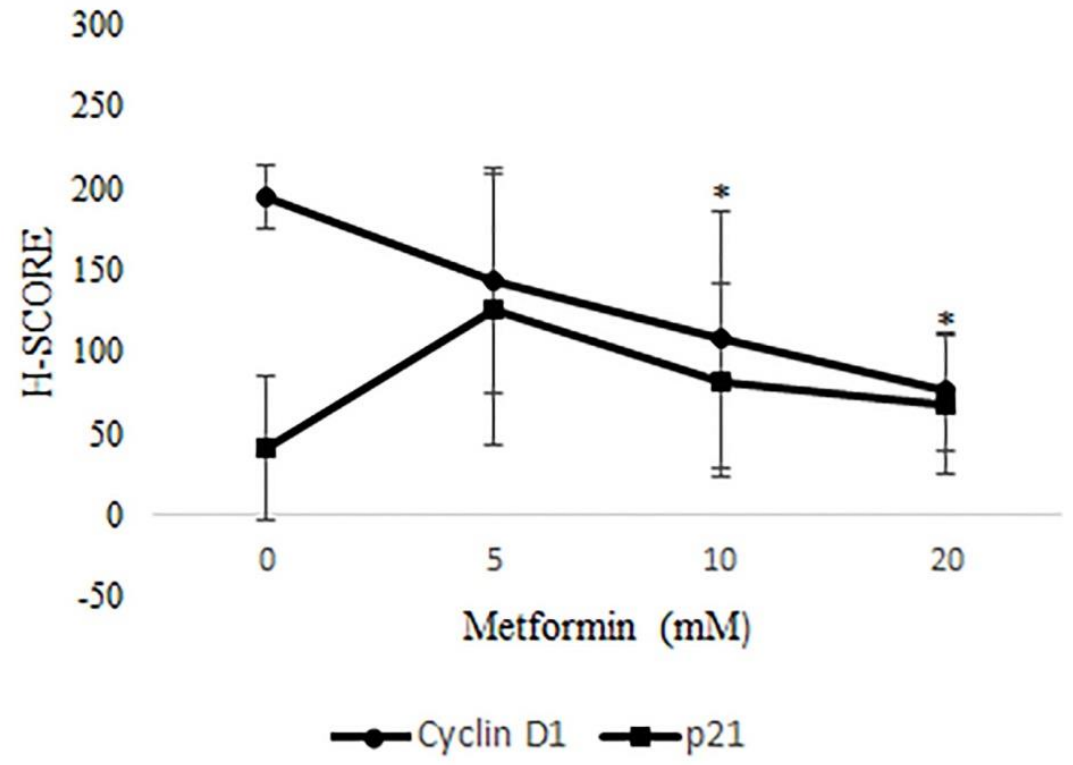

Figure 3. Metformin alters cyclin DI and p2I expression levels. Metformin decreases cyclin DI expression levels. p2I expression levels was increased after metformin treatment but is not statistically significant. Data presented as mean \pm standard deviation. $* p<0.05$ versus control. 
Metformin also altered E2F1 expression levels. Significant increased E2F1 expressions were observed at $5 \mathrm{mM}$ and 10 $\mathrm{mM}$ metformin. Metformin sharply reduced E2F1 expression at $5 \mathrm{mM}$. Moderate reduction of E2F1 was found at $10 \mathrm{mM}$ metformin. Metformin also reduced at $20 \mathrm{mM}$ metformin but is not statistically significant (Fig. 4).

\section{DISCUSSION}

p53 has pivotal role in cancer development by controlling cell homeostasis. It regulates cell growth and cell senescence by apoptosis, cell cycle, and DNA repair regulatory mechanism. Dysregulation of p53 and its related molecules functions causes uncontrolled cell growth leading to malignancy. Mutation in p53 gene has been reported in half of colorectal cancer case.

p53 controls intrinsic apoptosis pathway by activating pro apoptosis activities. By targeting several genes such as Bax, noxa and puma, p53 could induce cytochorme-c release into cytoplasm from mitochondria. This processes lead to protease cascade which end to cell execution by caspase-3. p53 contribution in extrinsic apoptosis pathway was also reported. p53 regulates extrinsic apoptosis pathway related molecules such as Fas ligand which subsequently induce apoptosis.

Cell cycle is a complex system which regulate cell proliferation. Cell cycle controlled by interaction of several molecules such as cyclins and cyclin dependent kinases (CDKs). For example, cyclin D1 promotes cell progression in $\mathrm{G} 1$ phase when cyclin $\mathrm{E}$ promotes progression in mid late G1 phase and early $\mathrm{S}$ phase. This processes induced by formation complex with CDKs. CDK4 and CDK6 activity relates to cyclin D1 and CDK2 relates to cyclin $\mathrm{E}$ function. Moreover, cyclins-CDKs complexes could phosphorylate $\mathrm{Rb}-\mathrm{E} 2 \mathrm{~F} 1$ complexes protein which lead to E2F1 release. E2F is a family molecules which responsible to up regulation of cancer promoting genes such as CCNE, CCNA and Myc.

\section{Metformin inhibits E2FI expression levels}

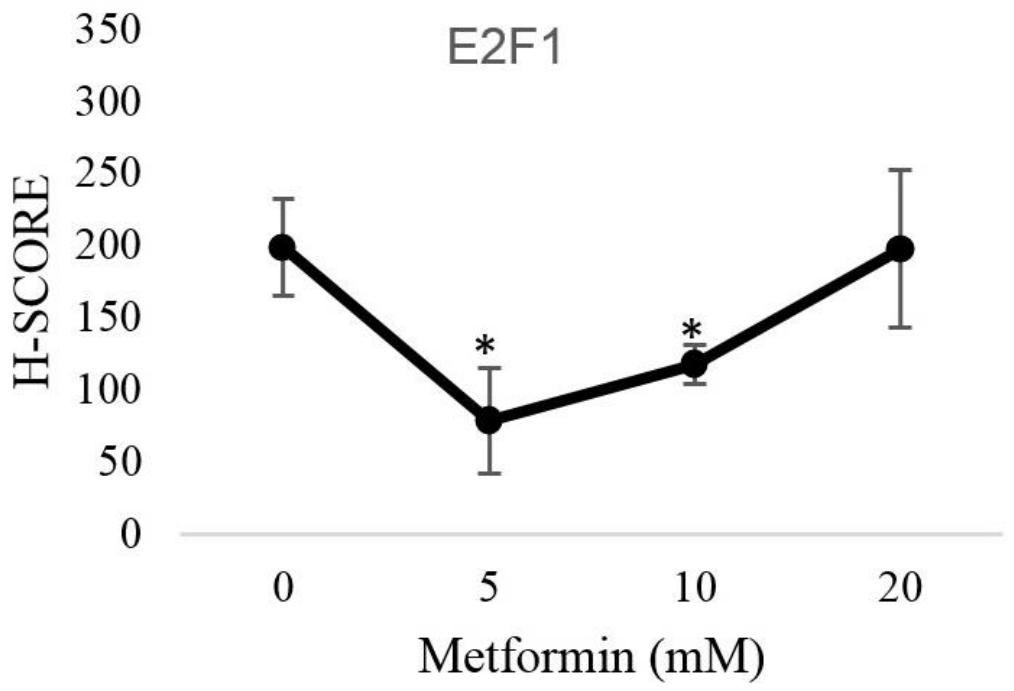

Figure 4. Metformin decreases E2FI expression levels. At $5 \mathrm{mM}$ and $10 \mathrm{mM}$ concentrations, metformin significantly decreases E2FI expression levels. Data presented as mean \pm standard deviation. $* p<0.05$ versus control. 

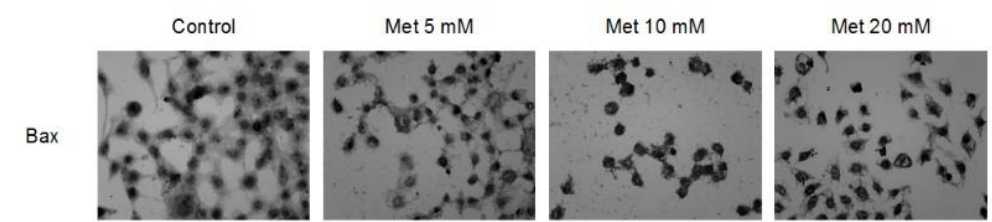

p21
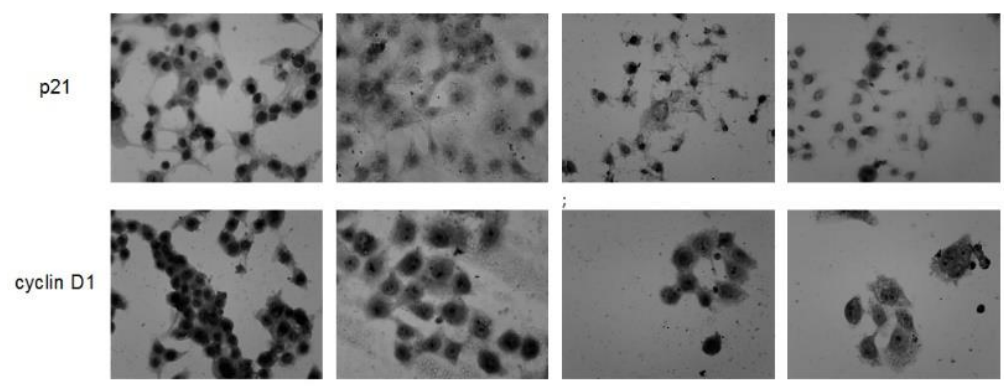

E2F1
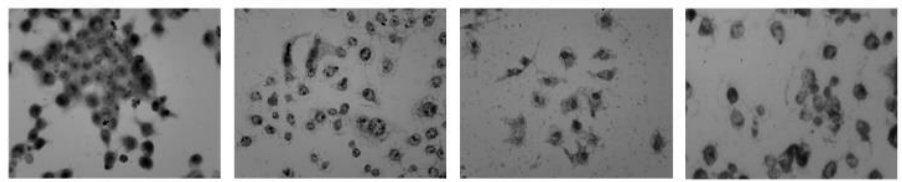

Figure 5. Metformin alters p53-related molecules in WiDr cell line. Representative image (magnification $x$ 400) of IHC analysis after metformin treatment in WiDr cell line.

p21 is a p53 related protein which also regulate cell cycle. Harper and colleagues reported that $\mathrm{p} 21$ is potent inhibitor of CDKs such as CDK2, CDK4, and CDK6. Impairment of cyclins and CDKs complexes result in cell cycle arrest.

In our study, we used WiDr cell line to evaluate effects of metformin in p53 deficient colon cancer cell line. We reported that metformin induced Bax expression significantly (Fig. 2). Our finding consistent to previous study by Buzzai and colleagues. They reported that metformin induced Bax expression in p53 deficient colon cancer cell line. As per Suzuki, et al. report, Bax could be induced by $\mathrm{p} 19$ in a p53 independent pathway.

In this study, metformin induced p21 expression but is not statistically significant (Fig. 3). Takhahasi and colleagues also found that increase of $\mathrm{p} 21$ expression by metformin could be in a functional p53 independent pathway. p21 which is normally transcriptional target by p53 could be induced by others mechanisms such as post transcriptional and post translational mechanism.
These events followed by decrease of cyclin D1 (Fig. 3) and and its downstream target, E2F1 (Fig. 4), significantly. Metformin is a LKB1/AMPK pathway activator drug. Activated AMPK could alter its downstream target including cyclin D1 (20). Zhuang and Miskimins Reported that metformin induced AMPK activity which subsequently decreased cyclin D1 expressions. Decrease of cyclin D1 expression would also reduce Rb-E2F1 complexes phosphorylation thus decrease E2F1 release and activity.

\section{CONCLUSIONS}

Our study supports previous studies which evaluate effect of metformin for cancer treatment in vitro. Moreover, its results also indicates metformin treatment could influence p53 related molecules in p53 mutant colon cancer cell line. Thus metformin treatment might beneficial for p53 mutated colon cancer patients. 


\section{ACKNOWLEDGEMENTS}

Financial supports: no funding supports reported. Conflict of interest: authors declare no conflict of interest. Contributors: AM, DRB, MRM, YCW, ANP, and DHP designed the study. MRM and YCW conducted cell culture and immunohistochemistry. DRB, MRM, and YCW provided immunohistochemistry data and analyzed it. AM, DRB, MRM, YCW, ANP, and DHP discussed the result and direction this project. AM supervised the project. DRB, MRM and YCW wrote the manuscript.

\section{REFERENCES}

Alimova, I.N., Liu, B., Fan, Z., Edgerton, S.M., Dillon, T., Lind, S.E., et al., 2009, Metformin Inhibits Breast Cancer Cell Growth, Colony Formation and Induces Cell Cycle Arrest in vitro, Cell Cycle, 8(6), 909-9I5.

Buzzai, M., Jones, R.G., Amaravadi, R.K., Lum, J.J., DeBerardinis, R.J., Zhao, F., et al., 2007, Systemic Treatment with The Antidiabetic Drug Metformin Selectively Impairs P53-Deficient Tumor Cell Growth, Cancer Res., 67(14):6745-6752.

Fradley, M.G., Barrett, C.D., Clark, J.R. and Francis, S.A., 2013, Ventricular Fibrillation Cardiac Arrest Due to 5fluorouracil Cardiotoxicity, Tex. Heart Inst. J., 40(4), 472-476.

Hosono, K., Endo, H., Takahashi, H., Sugiyama, M., Sakai, E., Uchiyama, T., et al., Metformin Suppresses Colorectal Aberrant Crypt Foci in a Short-term Clinical Trial, Cancer Prev. Res., 3(9), 1077-1083.

Hardie, D.G., 20I3, The LKBI-AMPK Pathwayfriend or Foe in Cancer?, Cancer Cell, 23(2), $|3|-\mid 32$.

Harper, J.W., Elledge, S.J., Keyomarsi, K., Dynlacht, B., Tsai, L.H., Zhang, P., et al., 1995, Inhibition of CyclinDependent Kinases by p2I, Mol. Biol. Cell, 6(4), 387-400.

Harris, S.L. and Levine, A.J., 2005, The p53 Pathway: Positive and Negative
Feedback Loops, Oncogene, 24(17), 2899-2908.

Jemal, A., Bray, F., Center, M.M., Ferlay, J., Ward, E. and Forman, D., 200 I, Global Cancer Statistics, CA Cancer J. Clin., 6 I (2), 69-90.

Labianca, R., Nordlinger, B., Beretta, G.D., Brouquet, A., Cervantes, A. and On behalf of the ESMO Guidelines Working Group, 2010, Primary Colon Cancer: ESMO Clinical Practice Guidelines for Diagnosis, Adjuvant Treatment and Follow-up, Ann. Oncol., 21 5, v70-v77.

lacopetta, B., 2003, TP53 Mutation in Colorectal Cancer, Hum. Mutat., 2 I (3), 27|-276.

Landman, G.W., Kleefstra, N., van Hateren, K.J., Groenier, K.H., Gans, R.O. and Bilo, H.J., 2010, Metformin Associated with Lower Cancer Mortality in Type 2 Diabetes: ZODIAC-16, Diabetes Care, 33(2), 322-326.

Lee, M.H. and Yang, H.Y., 2003, Regulators of GI Cyclin-Dependent Kinases and Cancers, Cancer Metastasis Rev., 22(4),435-449.

O'Connor, E.S., Greenblatt, D.Y., LoConte, N.K., Gangnon, R.E., Liou, J.I., Heise, C.P., et al., 20II, Adjuvant Chemotherapy for Stage II Colon Cancer with Poor Prognostic Features, J. Clin. Oncol., 29(25), 338I-3388.

Queiroz, E.A., Puukila, S., Eichler, R., Sampaio, S.C., Forsyth, H.L., Lees, S.J., et al., 2014, Metformin Induces Apoptosis and Cell Cycle Arrest Mediated by Oxidative Stress, AMPK and FOXO3a in MCF-7 Breast Cancer Cells, PLoS One, 9(5), e98207.

Shackelford, D.B. and Shaw, R.J., 2009, The LKBI-AMPK Pathway: Metabolism and Growth Control in Tumour Suppression, Nat. Rev. Cancer, 9(8), 563-567.

Stanelle, J., Stiewe, T., Theseling, C.C., Peter, M. and Pützer, B.M., 2002, Gene Expression Changes in Response to E2FI Activation, Nucleic Acids Res., 30(8), I859-1867.

Suzuki, H., Kurita, M., Mizumoto, K., Nishimoto, I., Ogata, E. and Matsuoka, M., 2003, pl9ARF-induced p53Independent Apoptosis Largely Occurs 
Through BAX, Biochem. Biophys. Res. Commun., 3 I 2(4), I273-I277.

Takahashi, A., Kimura, F., Yamanaka, A., Takebayashi, A., Kita, N., Takahashi, K., et al., 2014, Metformin Impairs Growth of Endometrial Cancer Cells Via Cell Cycle Arrest and Concomitant Autophagy and Apoptosis, Cancer Cell Int., I4, 53.

Zakikhani, M., Dowling, R.J., Sonenberg, N. and Pollak, M.N., 2008, The Effects of Adiponectin and Metformin On Prostate and Colon Neoplasia Involve
Activation of AMP-Activated Protein Kinase, Cancer Prev. Res., I (5), 369-375.

Zhang, Z.J., Zheng, Z.J., Kan, H., Song, Y., Cui, W., Zhao, G., et al., 20Il, Reduced Risk of Colorectal Cancer with Metformin Therapy in Patients With Type 2 Diabetes: a Meta-Analysis, Diabetes Care, 34(I0), 2323-2328.

Zhuang, Y. and Miskimins, W.K., 2008, Cell Cycle Arrest in Metformin Treated Breast Cancer Cells Involves Activation of AMPK, Downregulation of Cyclin DI, and Requires p27Kipl or p2 I Cip I, J. Mol. Signal, 3, I8. 